\title{
A Randomized Controlled Trial of 2 Inhalation Methods When Using a Pressurized Metered Dose Inhaler With Valved Holding Chamber
}

\author{
Divya Stephen RN MSN, Manju Vatsa RN MSN PhD, Rakesh Lodha MD, and \\ SK Kabra MD DNB
}

\begin{abstract}
BACKGROUND: Information on the comparative efficacy of single deep breathing versus tidal breathing for inhaled asthma medications is limited, although such information can be of much use for the treatment of patients suffering from asthma. The objective of the present study was to compare the relative difference in improvement in peak expiratory flow (PEF) with single maximal inhalation with breath-holding versus 5 tidal breaths during inhalation of salbutamol from a pressurized metered dose inhaler (pMDI) with valved holding chamber (VHC) in children 5-15 y of age with asthma. METHODS: The randomized controlled trial was carried out on children with asthma between 5 and $15 \mathrm{y}$ of age using a pMDI with a VHC either by a single deep breath with breath-hold or 5 tidal breaths. The experimental group received $200 \mu \mathrm{g}$ of salbutamol from the pMDI with VHC with a single maximal inhalation and breath-hold technique, whereas the control group received $200 \mu \mathrm{g}$ of salbutamol from pMDI with $\mathrm{VHC}$ using the 5 tidal breaths technique. The outcome variable, PEF, was reassessed 30 min after salbutamol use. RESULTS: Eighty-two subjects (mean age $8.79 \pm 2.5 \mathrm{y}, 65$ boys and 17 girls) were analyzed. There was significant improvement in the PEF, from baseline (pre-intervention) to post-intervention within the single maximal inhalation with breath-hold group and tidal breathing group independently $(P<.001)$. The mean difference in improvement in PEF between the single maximal inhalation with a breath-hold and 5 tidal breaths group was $30.0 \pm 18.16$ and $28.29 \pm 13.94 \mathrm{~L} / \mathrm{min}$, respectively, and was not statistically significant $(P=.88)$. CONCLUSIONS: Single maximal inhalation with a breath-hold technique is not superior to tidal breathing for improvement in PEF following salbutamol inhalation. Either method may be used in children between 5 and $15 \mathrm{y}$ of age. (India's Clinical Trials Registry CTRI/2013/04/003559.) Key words: inhalation techniques, single maximal breath with a breath-hold, tidal breathing, salbutamol metered dose inhaler, valved holding chamber techniques, metered dose inhaler techniques. [Respir Care 2015;60(12):1743-1748. () 2015 Daedalus Enterprises]
\end{abstract}

\section{Introduction}

A pressurized metered dose inhaler (pMDI) with spacer is preferred asthma treatment method for children of all

\footnotetext{
Ms Stephen and Dr Vatsa are affiliated with the College of Nursing, and Drs Lodha and Kabra are affiliated with the Department of Pediatrics, All India Institute of Medical Sciences, New Delhi, India.

The authors have disclosed no conflicts of interest.

Correspondence: Manju Vatsa RN MSN PhD, College of Nursing, All India Institute of Medical Sciences, New Delhi 110029, India. E-mail: mvatsa2001@yahoo.co.in.
}

DOI: $10.4187 /$ respcare.03213 ages due to its greater convenience, more effective lung deposition, lower risk of adverse effects, and lower cost as per Global Strategy for Asthma Management and Prevention (GINA) report. ${ }^{1}$ Like other respiratory drug delivery systems, even when used correctly, the pMDI only delivers approximately $10-20 \%$ of the nominal dose per actuation or puff. Deposition may be lower in children due to differences in breathing pattern or in cases where the technique is less than optimal. ${ }^{2}$

Tidal breathing with a pMDI with spacer is as effective as the single breath method as per Scottish Intercollegiate Guidelines Network (SIGN) recommendations. ${ }^{3}$ A study on the deposition of aerosol in children suggests better deposition of the medication with a single maximal inhalation with breath-hold as compared with tidal breathing. ${ }^{4}$ 


\section{Single Deep Breath vs Tidal Breathing Using PMDI With Spacer}

Breath-holding is usually recommended after the aerosol inhalation, but there is limited information on the clinical importance of breath-holding in the case of children. It has been observed that, in adults, breath-holding only improves lung deposition after an extremely slow inhalation, which may be difficult for children to perform. ${ }^{5}$ Information on comparative efficacy of either method is limited.

Thus, the objective of the present study is to compare the relative improvement in peak expiratory flow (PEF) with a single maximal inhalation with breath-hold versus 5 tidal breaths during inhalation of salbutamol from a pMDI with valved holding chamber (VHC) in children 5-15 y of age with asthma.

\section{Methods}

The study was conducted between August and December 2012 at the out-patient pediatric chest clinic of a tertiary care hospital in New Delhi, India. Ethical clearance was obtained from the institutional ethics committee. Informed consent from parents and assent from children above $7 \mathrm{y}$ were also taken.

We enrolled children 5-15 y of age diagnosed with asthma by a physician and receiving inhalation therapy with a PMDI and VHC, who could perform the maneuver for measuring PEF and who could hold their breath for 5 s or more. Children with exacerbations of asthma (ie, as per Global Initiative for Asthma [GINA] report: breathlessness on walking or talking or at rest; breathing frequency $>30 / \mathrm{min}$; moderate or loud wheeze; accessory or suprasternal retractions; unable to talk in sentences; $\mathrm{S}_{\mathrm{aO}_{2}}$ on room air $<95 \%$ ); congenital abnormalities of the chest, cardiovascular or neuromuscular disease; anthropometric parameters less than third percentile; regular long-acting $\beta_{2}$ agonist (salmeterol, formoterol) use; and those who had received $\beta_{2}$ agonist (salbutamol), methylxanthines (theophylline), or anti-cholinergic drugs (ipratropium bromide) $6 \mathrm{~h}$ before the observation were excluded from the study.

The intervention, that is, single maximal inhalation with a breath-hold technique, was demonstrated by the investigator to the children in the experimental group, and they were asked to demonstrate in return to ensure that they followed the procedure. Children were administered 2 puffs of salbutamol using a pMDI (with an interval of $60 \mathrm{~s}$ between each puff, each puff being $100 \mu \mathrm{g}$ ) with a VHC (Zerostat VT spacer, Cipla, Mumbai, India; a small volume static free spacer with a valve) and asked to inhale through the inbuilt mouthpiece either by the 5 tidal breaths (control group) or single maximal inhalation with a breathhold (experimental group) of at least $5 \mathrm{~s}$ duration (maximum $10 \mathrm{~s}$ ) with each puff. The subject was then asked to exhale into the VHC without removing the mouthpiece. The mouthpiece of the VHC has small slitlike openings,

\section{QUICK LOOK}

\section{Current knowledge}

A pressurized metered dose inhaler (pMDI) with spacer is the preferred device for aerosol therapy for treatment of asthma in children. pMDIs have greater convenience, more effective lung deposition, lower risk of adverse effects, and lower cost. When used correctly, pMDIs only deliver approximately $10-20 \%$ of the nominal dose per actuation. Deposition may be lower in children due to differences in breathing pattern or in cases where the technique is less than optimal.

\section{What this paper contributes to our knowledge}

A single maximal inhalation with a breath-hold technique was not superior to the 5 tidal breathing technique in improving the peak expiratory flow in children with asthma who use a pMDI with a valved holding chamber. Children can be taught either of the methods in accordance with their ability to perform a particular technique or their preference for administration of inhaled medications for asthma.

which allow exhaled air to move out as the one-way valve closes the spacer chamber. For the tidal breathing method, the multiple breathing technique steps as per GINA ${ }^{6}$ and Indian Academy of Pediatrics Respiratory Chapter recommendations ${ }^{7}$ were followed. The children were able to take the medicine through the VHC without a mask. The duration of breath-hold was measured in seconds using a stopwatch. PEF after salbutamol inhaler use was assessed $30 \mathrm{~min}$ after the initial dose. In the event that a child, after being randomized into the experimental group, was unable to perform the breath-hold for at least $5 \mathrm{~s}$ during actual assessment with salbutamol, then the subject was considered as attrition.

PEF was assessed using a peak expiratory flow meter (Breathe-O-meter, Cipla, Mumbai, India) with the subject in standing position. The inter-class consistency in obtaining PEF between the investigator and the asthma clinic staff was assessed among 10 children suffering from asthma and was found to be $99.6 \%$. Three consecutive readings for each child were taken, from which the best value was recorded. If a reading was hindered due to cough or sneeze, it was not considered.

The sample size was calculated based on the pilot study performed on 10 subjects. At the end of the pilot study, assuming that the baseline PEF values are the same in both groups, the improvement in PEF from baseline was found to be $32.6 \pm 9 \mathrm{~L} / \mathrm{min}$ in the experimental group and $27.6 \pm 9 \mathrm{~L} / \mathrm{min}$ in the control group. Computing the above 


\section{Single Deep Breath vs Tidal Breathing Using pMDI With Spacer}

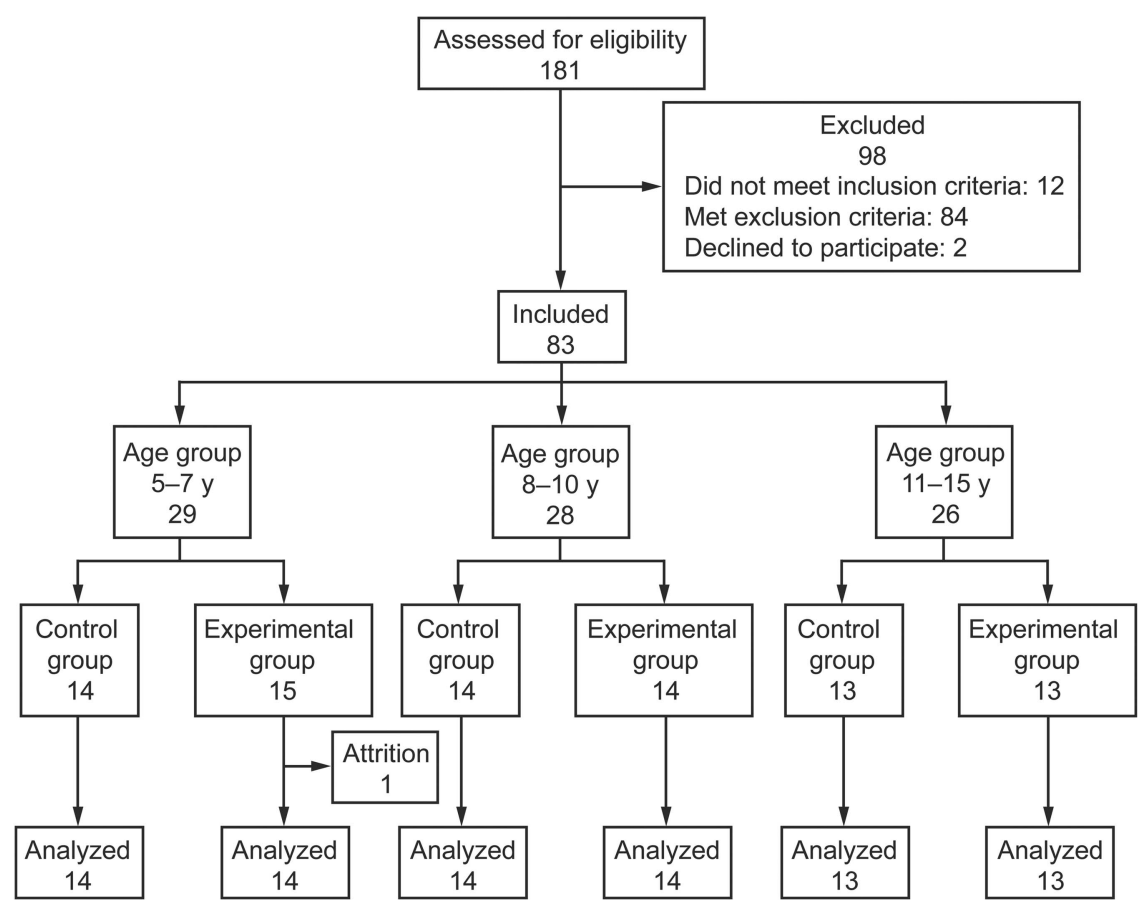

Fig. 1. Flow chart. The experimental groups performed a single maximal inhalation with breath-hold, and the control groups performed 5 tidal breaths.

values with an alpha of $5 \%$ and power of $80 \%$ and $1: 1$ ratio, by the method of change, we needed to enroll 37 in each group, ie, 74 cases. Considering an expected attrition rate of $10 \%$, it was decided to enroll 82 cases (41 in each arm).

The children's ability to perform a single maximal inhalation with breath-hold technique can vary with age. To address this issue, we stratified eligible children into age groups such as $5-7 \mathrm{y}, 8-10 \mathrm{y}$, and $11-15 \mathrm{y}$. Children in each strata were randomized into the single maximal inhalation with a breath-hold group or the 5 tidal breaths group using numbered opaque envelops for allocation concealment. Stratified randomization was achieved using a computerized random number generator (http://www. randomization.com/).

The data are represented as mean $\pm \mathrm{SD}$. The categorical data are represented as $n(\%)$ and were analyzed by applying chi-square test or Fisher's exact test, wherever necessary. The continuous data (ie, the mean improvement in PEF between the experimental and control groups) were analyzed using Student $t$ test or Mann-Whitney test wherever necessary. To find the improvement within each treatment modality for pre- and post-PEF values, paired $t$ test was applied. A $P$ value of $<.05$ was considered as statistically significant. Analysis of variance was used to compare breath-hold duration among the 3 age groups. SPSS 20.0 (SPSS, Chicago, Illinois) was used for statistical analysis.

\section{Results}

During the study period, 83 children were randomized into the experimental and control groups. One subject in the experimental group was considered as attrition, as he was unable to hold his breath for a minimum of $5 \mathrm{~s}$ during the actual performance and was therefore excluded. Thus, data from 82 subjects were available for final analysis, ie, 41 subjects in each arm (65 [79.3\%] boys and 17 [20.7\%] girls with a mean age of $8.8 \pm 2.5 \mathrm{y}$ ) were included (Fig. 1). The baseline characteristics of the study subjects are shown in Table 1.

Table 2 shows the comparison of improvement in PEF within as well as between the groups. There was significant improvement in the PEF, from baseline (pre-intervention) to post-intervention within the single maximal inhalation with breath-hold group and tidal breathing group independently at a $P$ value $<.001$. The mean difference in improvement in the PEF between the single maximal inhalation with a breath-hold and 5 tidal breath groups was $30.0 \pm 18.16$ and $28.29 \pm 13.94 \mathrm{~L} / \mathrm{min}$, respectively, and was not found to be statistically significant $(P=.88)$. The mean percentage improvement in PEF from baseline was $17.52 \pm 10.05 \mathrm{~L} / \mathrm{min}$ in the experimental group and $17.45 \pm 9.19 \mathrm{~L} / \mathrm{min}$ in the control group and was found to be comparable $(P=.82)$. A total of $16(39.0 \%)$ subjects in the single maximal group and $11(26.8 \%)$ subjects in the 


\section{Single Deep Breath vs Tidal Breathing Using pMDI With Spacer}

Table 1. Characteristics of the Study Subjects

\begin{tabular}{|c|c|c|c|}
\hline Variable & $\begin{array}{l}\text { Single maximal inhalation } \\
\text { with a breath }(n=41)\end{array}$ & $\begin{array}{l}5 \text { tidal breaths } \\
\quad(n=41)\end{array}$ & $P$ \\
\hline \multicolumn{4}{|l|}{ Age group* } \\
\hline $5-7$ y & $14(34.1)$ & $14(34.1)$ & \multirow[t]{3}{*}{$>.99$} \\
\hline $8-10$ y & $14(34.1)$ & $14(34.1)$ & \\
\hline $11-15 \mathrm{y}$ & $13(31.7)$ & $13(31.7)$ & \\
\hline \multicolumn{4}{|l|}{ Sex* } \\
\hline Male & $34(82.9)$ & $31(75.6)$ & \multirow[t]{2}{*}{.41} \\
\hline Female & $7(17.1)$ & $10(24.4)$ & \\
\hline \multicolumn{4}{|l|}{ Severity of asthma* } \\
\hline Severe persistent & $2(4.9)$ & $1(2.4)$ & \multirow[t]{4}{*}{.74} \\
\hline Moderate persistent & $20(48.8)$ & $18(43.9)$ & \\
\hline Mild persistent & $15(36.6)$ & $15(36.6)$ & \\
\hline Intermittent asthma & $4(9.8)$ & $7(17.1)$ & \\
\hline \multicolumn{4}{|l|}{ Exacerbations in past $1 \mathrm{y}^{*}$} \\
\hline None & $36(87.8)$ & $39(95.1)$ & \multirow[t]{3}{*}{.41} \\
\hline $1-2$ episodes & $4(9.8)$ & $2(4.9)$ & \\
\hline$>3$ episodes & $1(2.4)$ & 0 & \\
\hline \multicolumn{4}{|l|}{ Physician's assessment of asthma control* } \\
\hline Adequately controlled & $17(41.5)$ & $17(41.5)$ & \multirow[t]{2}{*}{$>.99$} \\
\hline Not adequately controlled & $24(58.5)$ & $24(58.5)$ & \\
\hline \multicolumn{4}{|l|}{ Reason for present visit* } \\
\hline Follow-up & $22(53.7)$ & $22(53.7)$ & \multirow[t]{2}{*}{$>.99$} \\
\hline Others & $19(46.3)$ & $19(46.3)$ & \\
\hline \multicolumn{4}{|l|}{ Inhalation technique child is using* } \\
\hline Single maximal inhalation with breath hold & $2(4.9)$ & 0 & \multirow[t]{3}{*}{.33} \\
\hline Tidal breathing & $23(56.1)$ & $26(63.4)$ & \\
\hline Do not know & $16(39.0)$ & $15(36.6)$ & \\
\hline \multicolumn{4}{|l|}{ Inhalation instruction* } \\
\hline Yes & $25(61)$ & $26(63.4)$ & \multirow[t]{2}{*}{.82} \\
\hline No & $16(39)$ & $15(36.6)$ & \\
\hline \multicolumn{4}{|l|}{ Inhalation method previously taught $* *(n=51)$} \\
\hline Tidal breathing & $24(96)$ & $26(100)$ & \multirow[t]{3}{*}{.30} \\
\hline \multirow[t]{2}{*}{ Single maximal inhalation with breath hold } & $1(4)$ & 0 & \\
\hline & $(n=25)$ & $(n=26)$ & \\
\hline \multicolumn{4}{|c|}{$\begin{array}{l}\text { Data represented as median (interquartile range) and frequency (\%). Total number of subjects was } 82 \text {. } \\
\text { *Chi-square test. }\end{array}$} \\
\hline
\end{tabular}

Table 2. Comparison of Improvement in PEF Between and Within the Groups

\begin{tabular}{lcc}
\hline \hline & $\begin{array}{c}\text { Group 1: Single maximal } \\
\text { inhalation with a breath } \\
\text { hold }(n=41)\end{array}$ & $\begin{array}{c}\text { Group 2: } 5 \text { tidal } \\
\text { breaths } \\
(n=41)\end{array}$ \\
\hline Baseline PEF (L/min) & $145.85 \pm 49.14^{*}$ & $144.39 \pm 58.82^{* *}$ \\
PEF 30 min after salbutamol inhalation (L/min) & $175.85 \pm 49.34^{*}$ & $172.68 \pm 60.95^{* *}$ \\
Improvement in PEF (L/min) & $30.0 \pm 18.16$ & $28.29 \pm 13.94$ \\
Percent improvement in PEF & $17.52 \pm 10.05$ & $17.45 \pm 9.19$ \\
& & .79 \\
Data are represented as mean \pm SD. Total number of subjects was 82. & & .82 \\
$* P$ value for within group comparison: $<.001$. & & \\
$* * P$ value for within group comparison: $<.001$. & & \\
PEF = peak expiratory flow & & \\
\hline
\end{tabular}




\section{Single Deep Breath vs Tidal Breathing Using pMDI With Spacer}

tidal breathing group showed a $>20 \%$ increase in PEF after salbutamol administration.

The mean breath-hold duration was assessed for $41 \mathrm{sub}-$ jects across all age groups and was found to be $9.2 \pm 1.4 \mathrm{~s}$ during the first actuation (puff) of pMDI; during the second actuation, it was $8.9 \pm 1.5 \mathrm{~s}$. Comparisons of breathhold duration in different age groups $(5-7 \mathrm{y}, 8-10 \mathrm{y}, 11-$ $15 \mathrm{y})$ during both first and second actuation were comparable $(P=.46$ and .54 in the first and second actuation, respectively). With the exception of one child in the 5-7 y category, all other children enrolled were able to perform the breath-hold maneuver in our study.

\section{Discussion}

In this study, we did not observe any significant difference in the improvement in PEF after inhalation of salbutamol using a pMDI and VHC by either single maximal inhalation with a breath-hold technique or 5 tidal breaths technique.

It has been observed that many children who suffer from asthma use their inhaler devices incorrectly, even after instruction for correct use. ${ }^{8,9}$ The most difficult skill for children using a metered-dose inhaler was progressive inhalation of the medicine slowly and deeply through the mouth and the need to hold their breath for a count of $10 .{ }^{10-12}$

A simple and efficient method to deliver drug through a pMDI in children must be identified to improve compliance and symptom control, and to minimize side effects. Patients can take a slow single breath to retrieve the medication or take tidal breaths from the chamber as per the Global Initiative on Asthma. There are very few studies done in this area in children to compare effectiveness of either method. The usual practice is to use the 5 tidal breath method. Therefore, we decided to compare the effectiveness of deep inhalation over tidal breathing during pMDI use.

We used PEF as the main outcome variable to assess the 2 inhalation techniques. Spirometry parameters including $\mathrm{FEV}_{1}$ may be more relevant as they are more sensitive markers to assess the response to bronchodilator. An alternative method to compare the 2 inhalation techniques may be the documentation of deposition of aerosol in lungs by radionuclear tracer.

We concluded that the single maximal inhalation with a breath-hold technique is not superior to the 5 tidal breath technique in improving the PEF in children with asthma using pMDI and VHC. The findings of our study are similar to the findings of James et al. ${ }^{13}$ They performed a cross-over design to demonstrate that there was no significant difference in $\mathrm{FEV}_{1}$ and $\mathrm{FEF}_{25-75 \%}$ with salbutamol pMDI delivered via a spacing device (Volumatic, $750 \mathrm{~mL}$ ) between the panting technique and single breath followed by a breath-hold maneuver in 21 subjects with a mean age of $10.9 \pm 3.3 \mathrm{y}$. There are limited data on clinical studies with a similar outcome on this topic.

There are several studies on drug deposition. Roller et $\mathrm{al}^{4}$ found that inhalation of the extra-fine formulation of ${ }^{99} \mathrm{~m}$ Tc-labeled hydrofluoroalkane-beclomethasone dipropionate with the breath-hold technique $(n=12)$ significantly improved lung deposition compared with tidal breathing $(n=12)$ across children $4-15$ y of age. The adjusted mean of lung deposition in the breath-hold group was 1.6 times higher than that in the tidal group in children $5-7$ y of age ( $n=4$ in each arm), although the difference was not statistically significant due to the small sample size. This is in contradiction to the findings of our study. However, this may be due to the difference in the outcome variable and the drug used.

Schultz et $\mathrm{al}^{14}$ tried to determine the number of breaths required to inhale salbutamol from different spacers/VHCs by recording breathing patterns of children 2-7 y of age. The children were asked to inhale placebo from 4 different spacers/VHCs, and their breathing patterns were simulated by a flow generator. The amount of drug deposition on inspiratory filters was used as the outcome to measure improvement in drug delivery. They demonstrated that single maximal inhalation (without breath-hold) did not result in improved drug delivery, compared with tidal breathing, for young children 2-7 y of age while inhaling salbutamol from different spacer/VHCs. This finding is similar to the findings of our study, although they are not comparable because the outcome variable and type of population used were different.

Studies have shown that there are inconsistencies with the technique of inhalation in the case of children (especially with the single maximal inhalation with a breathhold maneuver). In a few studies, the authors assessed appropriateness of pMDI techniques including ability to breath-hold, and they found that fewer than $50 \%$ of subjects could hold their breath for a minimum of $5 \mathrm{~s}$. Bhukart et $\mathrm{al}^{12}$ reported that the most common mistake in the pretest was the inability to hold the breath for at least $10 \mathrm{~s}$ after actuation (56\%). Even after training for pMDI use and assessing within a short time of 1-4 weeks after training, approximately one fifth of the children still exhibited incorrect pMDI use, especially failure to breath-hold. Chen et al ${ }^{15}$ also had similar results, in which they found that only $35.5 \%$ children could hold their breath for $10 \mathrm{~s}$. However, we found that children were able to breath-hold for $>5 \mathrm{~s}$ (mean duration of $9.2 \pm 1.4 \mathrm{~s}$ and $8.9 \pm 1.5 \mathrm{~s}$ during first and second actuations, respectively). Roller et $\mathrm{al}^{4}$ and Deerojanawong et al $^{16}$ also found that children included in the study were able to maintain the breath-hold for $\geq 5 \mathrm{~s}$.

The findings of this study may not be generalizable, as it was a hospital-based study. A major limitation of this study was the use of the PEF instead of detailed spirom- 


\section{Single Deep Breath vs Tidal Breathing Using PMDI With Spacer}

etry to assess outcome; although spirometry parameters are more sensitive, measuring PEF was more feasible and less time-consuming. PEF has a significantly larger degree of variability than $\mathrm{FEV}_{1}$, the accepted standard for the measurement of airway caliber. $\mathrm{FEV}_{1}$ may be as much as $35 \%$ lower or up to $15 \%$ higher than the PEF for patients with obstructive lung diseases. There is also a fairly wide normal range, and PEF measurements do not necessarily parallel those of $\mathrm{FEV}_{1}$. Children's ability to perform the breath-hold maneuver could have been influenced by the Hawthorne effect. We included only children older than $5 \mathrm{y}$, to ensure proper technique and measurement of PEF in the clinic. The investigator was not blinded to the intervention.

\section{Conclusions}

The single maximal inhalation with a breath-hold technique is not superior to the 5 tidal breath technique in improving the PEF in children with asthma who use pMDI with valved holding chamber. Children can, therefore, be taught either of the methods in accordance with their ability to perform a particular technique or their preference for administration of inhaled medications for asthma.

\section{ACKNOWLEDGMENTS}

We extend our gratitude to Dr Guresh Kumar (Department of Biostatistics, All India Institute of Medical Sciences, New Delhi, India) for the statistical analysis, Dr Sundaram (Department of Biostatistics, Amrita Institute of Medical Sciences, Kochi, India) for his advice, and Dr CS Francis (Department of English, Sacred Heart College, Thevara, India) for helping with the linguistic revision. We also thank all the participants who have consented for the study and the Department of Pediatrics (All India Institute of Medical Sciences, New Delhi, India) for providing the equipment used for the study.

\section{REFERENCES}

1. Global Initiative for Asthma (GINA). GINA report. Global strategy for asthma management and prevention: 2010. http://www.ginasthma. org/local/uploads/files/GINA_Report_2010_1.pdf. Accessed 14 May, 2015.
2. Gardenhire DS, Ari A, Hess D, Myers TR. A guide to aerosol delivery devices for respiratory therapists. 3rd edition. American Association for Respiratory Care: 2013. https://c.aarc.org/resources/ aerosol resources/aerosol guide rt.pdf. Accessed 14 May, 2015.

3. British Thoracic Society and Scottish Intercollegiate Guidelines Network. British guidelines on management of asthma. 2012. https:// www.brit-thoracic.org.uk/document-library/clinical-information/ asthma/btssign-guideline-on-the-management-of-asthma/. Accessed 14 May, 2015.

4. Roller CM, Zhang G, Troedson RG, Leach CL, Le Souëf PN, Devadason SG. Spacer inhalation technique and deposition of extrafine aerosol in asthmatic children. Eur Respir J 2007;29(2):299-306.

5. Pedersen S, Dubus JC, Crompton GK, ADMIT Working Group. The ADMIT series; issues in inhalation therapy: inhaler selection in children with asthma. Prim Care Respir J 2010;19(3):209-216.

6. Global Initiative for Asthma. How to use a spacer device. http:// www.ginasthma.org/local/uploads/files/volumatic.pdf. Accessed 15 May, 2015.

7. IAP respiratory chapter. Asthma by consensus; 2011. http://iapindia. org/iapfiles/Asthma-3.pdf. Accessed 15 May, 2015.

8. Pal R, Dahal S, Pal S. Prevalence of bronchial asthma in Indian children. Indian J Community Med 2009;34(4):310-316.

9. Pearce N, Aït-Khaled N, Beasley R, Mallol J, Keil U, Mitchell E, et al. Worldwide trends in the prevalence of asthma symptoms: phase III of the International Study of Asthma and Allergies in Childhood (ISAAC). Thorax 2007;62(9):758-766.

10. Rubin BK, Fink JB. The delivery of inhaled medication to the young child. Pediatr Clin North Am 2003;50(3):717-731.

11. Linda BL, Celano M, Geller RJ, Phillips KM. Development of a scale to measure children's metered-dose inhaler and spacer technique. Ann Allergy Asthma Immunol 1996;7(3):217-221.

12. Bhurkhart PV, Rayens MK, Bowman RK. An evaluation of children's metered dose inhaler technique for asthma medications. Nurs Clin North Am 2005;40(1):167-182

13. James RW, Masters IB. Single breath versus panting technique in salbutamol delivery through a $750 \mathrm{~mL}$ spacing device. Pediatr Pulmonol 1990;8(4):263-267.

14. Schultz A, Le Souëf TJ, Venter A, Zhang G, Devadason SG, Le Souëf PN. Aerosol inhalation from spacers and valved holding chambers requires few tidal breaths for children. Pediatrics 2010;126(6): 1493-1498.

15. Chen SH, Yin TJ, Huang JL. An exploration of the skills needed for inhalation therapy in school children with asthma in Taiwan. Ann Allergy Asthma Immunol 2002;89(3):311-305.

16. Deerojanawong J, Sakolnakorn VP, Prapphal N, Hanrutakorn C, Sritippayawan S. Evaluation of metered-dose inhaler administration technique among asthmatic children and their caregivers in Thailand. Asian Pac J Allergy Immunol 2009;27(2-3):87-93.

This article is approved for Continuing Respiratory Care Education credit. For information and to obtain your CRCE

(free to AARC members) visit www.rcjournal.com

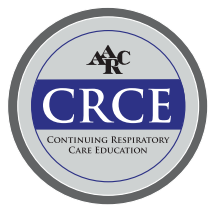

